\title{
Absolute and Relative Activity of Microencapsulated Natural Essential Oils against the Larvae of Carpet Beetle Anthrenus flavipies (LeConte)
}

\author{
Jayant Udakhe, ${ }^{1}$ Neeraj Shrivastava, ${ }^{1}$ Smita Honade, ${ }^{1}$ \\ Dhanashree Banait, ${ }^{2}$ and Namita Sonawane ${ }^{2}$ \\ ${ }^{1}$ Textile Chemical and Colour Department, Wool Research Association, Thane 400607, India \\ ${ }^{2}$ Department of Fibres and Textile Processing Technology, I.C.T., Mumbai 400019, India
}

Correspondence should be addressed to Jayant Udakhe; jsudakhe@wraindia.com

Received 18 July 2014; Accepted 19 October 2014; Published 12 November 2014

Academic Editor: Phillip W. Gibson

Copyright ( 2014 Jayant Udakhe et al. This is an open access article distributed under the Creative Commons Attribution License, which permits unrestricted use, distribution, and reproduction in any medium, provided the original work is properly cited.

This study focuses on finding natural ecofriendly alternatives to the existing commercial Anthrenus flavipies resist chemicals. Eucalyptus, lavender, and citronella microcapsules were explored as natural alternatives. Chemical contents of microcapsules and fragrance releasing property were tested using gas chromatography. Absolute (proofing) and relative (repellent) activities of microcapsule treated fabrics were tested against the larvae of carpet beetle Anthrenus flavipies (LeConte). Proofing activity test results revealed that natural essential oils act as a deterrent for Anthrenus flavipies, but give lesser protection compared to commercial chemical permethrin. Repellency test results also affirmed these findings and it was observed that Anthrenus flavipies prefers to eat untreated fabric compared to its treated counterpart.

\section{Introduction}

The damage to the woollen textile products, hair, feather, and fur by wool moth (insect that feeds on woolen textiles) has been a continuing subject of investigation over the years. The damage to the woollen textiles by moth larvae throughout the world is estimated to cost millions of dollars every year. Clark [1] and Hartley et al. [2] have estimated the damage caused by a single larva to be 92.5 pounds in one year and 100 pounds in 280 days, respectively. Thus, moth proofing is very essential to wool for its long life as it is a costly commodity. Without effective moth proofing this damage would increase further and will cause permanent damage to wool which is considered as high quality natural bicomponent textile fibre. The insects usually remain undetected until the damage has occurred. Fabrics, of course, can be damaged by textile pests within a few weeks of initial infestation.

Different kinds of commercial finishing treatments are given to the wool product. Some of the colourless preparations available are Dieldrin [3], Mitin LP [4], Eulan WA
[5], and synthetic pyrethroid permethrin [6, 7]. These moth proof chemicals are generally applied in a single bath during the dyeing of wool. Continuous discharge of dyeing effluents containing these chemicals provide significant toxic load to each of the affected effluent treatment systems and associated downstream river area. Permethrin has been shown to be highly toxic for aquatic arthropods, fish, and honey bees because they have lower levels of carboxyl esterase activity than mammals [8].

For any effective insecticidal (moth proof) finish to be used sustainably in the near future, it should have biodegradability as well as low mammalian and aquatic toxicity. There are natural insecticidal alternatives available such as natural pyrethrins. The natural pyrethrins which are insecticidal esters from Chrysanthemum cinerariaefolium (Compositae) are superior to many other synthesized insecticides in their quick-killing power, low mammalian toxicity, biodegradability, and relatively low resistance development in insects [911]. Many plants contain compounds that act in preventing attack from phytophagous (plant eating) insects. These 
chemicals fall into several categories, including repellents, feeding deterrents, toxins, and growth regulators. Most of them can be grouped into five major chemical categories, that is, nitrogen compounds (primarily alkaloids), terpenoids, phenolics, proteinase inhibitors, and growth regulators. The repellency of plant materials to certain insects has well been exploited for thousands of years by humans, most simply by hanging bruised plants in houses, a practice that is still in wide use throughout the developing countries. Plants like eucalyptus, lavender, and citronella are well reported to have insect repellent properties especially against mosquito [1216].

The aim of this work was to study and explore natural essential oils for their activity against the larvae of carpet beetle Anthrenus flavipies (LeConte). Activity of these essential oils in terms of proofing and repellency is rarely reported in the literature. Microencapsulated natural essential oils for example, citronella, lavender, and eucalyptus oils were characterized for their chemical compositions using gas chromatography-mass spectroscopy (GC-MS). Wool fabrics were treated with these microcapsules and analyzed for their proofing and repellent activity along with the release of fragrance. The durability of these treatments to washing and dry-cleaning was also reported.

\section{Materials and Methods}

2.1. Materials. Microencapsulated citronella, lavender, and eucalyptus natural essential oils were supplied by Tanishka Products, Mumbai (India). Wool fabric was procured from Bhutti weaver's co-operative society Ltd., H.P. (India). Merino wool fabric $(22.5 \mu \mathrm{m}$ wool, warp, and weft count of $2 / 47 \mathrm{Nm}$, $2 / 2$ twill weave, 52/40 EPI/PPI) was used in the study. Imerol PCJ liquid (wetting agent) was supplied by Clariant India Limited, Mumbai (India). Eulan SPA was supplied by Tanatex Chemicals India Pvt. Ltd., Thane (India). All other chemicals used were LR grade.

2.2. Fabric Scouring. In order to remove lubricants and antistatics, fabric was scoured using $0.5 \%$ (on the weight of fabric) Imerol PCJ liquid (wetting agent) at $60^{\circ} \mathrm{C}$ for $30 \mathrm{~min}$ at material to liquor ratio of $1: 30$, hydro extracted, dried at room temperature, and used for further treatments.

2.3. Application of Permethrin (Eulan SPA). Eulan SPA (commercial insects resist agent) was applied on to the wool fabric by exhaustion process. A concentration of $0.125 \% \mathrm{v} / \mathrm{w}$ Eulan SPA (recommended by International Wool Secretariat) was used in this study. The applied concentration was of level 3, which imparts appropriate protection to woollens to be used in warmer, drier climates against the carpet beetle Anthrenus flavipies (LeConte) [17]. Along with Eulan SPA, 2.5 gpl sodium acetate, $2.5 \mathrm{gpl}$ acetic acid, and 5 gpl lyogen WSN (levelling agent) were used. Material to liquor ratio was kept at $1: 20$. The bath was heated up to $100^{\circ} \mathrm{C}$ with a rate of rise of $3^{\circ} \mathrm{C} / \mathrm{min}$ and held for $60 \mathrm{~min}$ for complete exhaustion. Then, the sample was washed with cold water and dried at room temperaure.
2.4. Application of Microcapsules. The formulations were prepared using $0.5 \mathrm{gpl}$ Imerol PCJ liquid and 20 gpl microencapsulated citronella, lavender, and eucalyptus oils. The $\mathrm{pH}$ of the solutions was maintained at 4.5. The wool fabric was soaked in the solution for $15 \mathrm{~min}$. Afterwards the fabric was padded with a wet pick up of $80 \%$, dried at $100^{\circ} \mathrm{C}$, and cured at $130^{\circ} \mathrm{C}$ for $2 \mathrm{~min}$.

2.5. Durability to Washing and Dry-Cleaning. For testing durability of finished fabrics, all samples were washed three times using Electrolux Wascator (Model FOM 71 CLS) laboratory washing machine with $7 \mathrm{~A}$ washing programme as per standard test method TM 31 and fabric was also separately dry-cleaned three times as per standard test method ISO 3175-2 (1998).

\section{Testing and Characterization}

3.1. Particle Size Analysis. The particle size analysis was carried out using Malvern Mastersizer 2000 model with Laser light scattering principle. Microcapsules of eucalyptus, citronella, and lavender were tested in emulsion state using Hydro 2000S accessory.

3.2. Solid Capsule Contents. The microcapsules slurry (10 gm) was dried at $60^{\circ} \mathrm{C}$ for $6 \mathrm{hrs}$ and final weight of dried capsule was taken. Solid content was determined from initial and final weight of the capsule slurry.

3.3. Extraction of Essential Oils from Capsules and Fabric Samples. The dried capsules were crushed using Retsch MM 400 mixer mill machine in the presence of hexane using $10 \mathrm{~mm}$ stainless steel balls. The frequency of oscillation was kept at 20 cycles/second for 15 min; similar method was used for extraction of essential oil from unwashed, washed, and dry-cleaned fabrics. The extracts were then analyzed using GC-MS to determine the essential oil contents in capsules as well as in fabric samples.

3.4. Gas Chromatography Mass Spectrometry (GC-MS) Anal$y$ sis. The chemicals present in eucalyptus, citronella, and lavender essential oils were analyzed using GC-MS system. Thermo Scientific Focus GC-DSQ II system was used in the study. Helium was used as a carrier gas, with an injector temperature of $230^{\circ} \mathrm{C}$. The initial oven temperature was kept at $80^{\circ} \mathrm{C}$ for $2 \mathrm{~min}$ which was further increased to $280^{\circ} \mathrm{C}$ at $10^{\circ} \mathrm{C} / \mathrm{min}$ and held for $10 \mathrm{~min}$. Spit ratio used was 1:20. The analysis was done using MSD detector. Component identification was carried out by comparing the obtained MS data with those reported in Library. The amount of essential oils present in the capsules, unwashed, washed, and drycleaned fabric was estimated against standard essential oil samples.

3.5. High Performance Liquid Chromatography (HPLC) Anal$y$ sis. The sensitivity of permethrin in GC-MS was observed to be less. Hence, the analysis of permethrin content in unwashed, washed, and dry-cleaned fabric was carried out 
using HPLC. The permethrin treated samples were refluxed in methanol for $3 \mathrm{hrs}$ and the extracts were analyzed using HPLC system.

3.6. Scanning Electron Microscopy (SEM). Wool fabric samples were coated with gold using JEOL JEC-550 twin coater before carrying out scanning electron microscopy. JEOL JSM-5400 scanning electron microscope was used for sample analysis. The surface morphologies of untreated, citronella unwashed, washed, and dry-cleaned samples were studied.

\subsection{Intensity of Fragrance}

3.7.1. Qualitative Evaluation. The relative intensity of fragrance was evaluated by a panel of ten evaluators. All evaluators were asked to take two-three whiffs of unwashed, washed, and dry-cleaned fabric samples. Samples were rated according to intensity of fragrance as very strong, strong, moderate, faint, and very faint. The evaluators were also given a smell of coffee beans in between to neutralize the fragrance of previous samples.

3.7.2. Quantitative Evaluation. The release rate of fragrance was tested over a period of 15 days at an interval of every five days. The eucalyptus, citronella, and lavender treated unwashed samples were kept in incubator at $37 \pm 2^{\circ} \mathrm{C}$ to simulate human body temperatures. Qualitative analyses were also performed for these samples. The total essential oil content was determined using GC-MS system. The release rate was then calculated using the following formula:

$$
\begin{aligned}
\text { Release } \%= & \frac{\text { Initial concentration }- \text { Final concentration }}{\text { Initial concentration }} \\
& \times 100 .
\end{aligned}
$$

3.8. Proofing Testing against the Larvae of Anthrenus flavipies. The biological assays were done with the larvae of Anthrenus flavipies (LeConte) according to visual observation of the extent of damage, weight loss of the test sample, and larval condition of the test larvae as per the procedure described by ISO 3998-1977 (E). The untreated and treated fabric samples were cut into discs of $40 \mathrm{~mm}$ diameter and conditioned at $65 \pm 2 \%$ relative humidity at $27 \pm 2^{\circ} \mathrm{C}$ temperature for $24 \mathrm{hrs}$ and initial weight was noted down. The larvae of Anthrenus flavipies (LeConte) available at Wool Research Association were used for evaluation. Eleven-week-old larvae weighing about 0.8 to $1.2 \mathrm{mg}$ were used for the test. The fabric samples of known weights were placed in contact with 15 larvae in glass Petri dishes for 14 days in controlled atmosphere of $27 \pm 2^{\circ} \mathrm{C}$ temperature and $65 \pm 2 \%$ relative humidity in a dark cabinet. Samples were weighted after completion of test. The loss in mass $(\Delta m)$ of each test specimen and voracity control, due to feeding, was determined as follows:

$$
\Delta m=\frac{m_{0} \times m_{3}}{m_{2}}-m_{1},
$$

where $m_{0}$ is the mass of the test specimen or voracity control before exposure to larvae; $m_{1}$ is the mass of the test specimen or voracity control after exposure to larvae; $m_{2}$ is the mean initial mass of appropriate moisture regain controls; $m_{3}$ is the mean final mass of appropriate moisture regain controls.

All the samples were assessed for damage by visual observation in terms of extent of cropping and holes formation. The larvae condition was also accessed in terms of live, dead, or pupating.

3.9. Repellency Testing against the Larvae of Anthrenus flavipies. To study the repellent activity of the finished fabric, we have devised a test method based on ISO 3998-1977 (E). In this test two fabric samples were kept in single dish in which one sample was untreated and the other one was finished. This test was designed to study the preference of moth for a particular fabric. All other testing parameters of ISO 39981977 (E) were unchanged.

\section{Results and Discussion}

Detailed chemical composition of the citronella, lavender, and eucalyptus essential oils is shown in (Table 1). It was found that eucalyptol is major chemical constituent of the eucalyptus oil and comprises about $82 \%$ of total volume. Citronellal (45\%) is major chemical content present in the citronella oil. Isononyl ester is major component of Lavender oil and contributes $26 \%$ of the total volume. These major chemical components impart characteristic fragrance to the respective essential oils.

Average particle size (Table 2) of microencapsulated eucalyptus, lavender, and citronella essential oils in terms of volume weighted mean was found to be in the range of 3$5 \mu \mathrm{m}$ with mean specific surface area of $1-2 \mathrm{~m}^{2} / \mathrm{g}$.

Solid polymer content (Table 3) ranged from 34 to $37 \%$ for microcapsules used in this research. Loading of essential oil inside the microcapsules was found to be in the range of $24-41 \%$ on the basis of microcapsule slurry.

Lavender essential oil content was found to be higher on the unwashed finished fabric compared to other two essential oils (Table 4). Capsules were not found to be durable for washing process as essential oil content reduces up to trace level. Dry-cleaning treatment also reduced the essential oil content on the fabric. Loss of finish due to washing was greater than that of dry-cleaning, as the washing treatment is far more severe than that of dry-cleaning. Permethrin content was also found to reduce after washing and dry-cleaning but being a small molecule permethrin penetrates into the fibre structure and remains inside, thus showing better durability to washing and dry-cleaning processes.

SEM images (Figure 1) of citronella capsules treated fabric have shown uniform distribution of capsules on the fibre surface. After washing, most of the capsules get removed and few capsules can be seen on the fabric surface. Dry-cleaning also reduced the capsule content and presences of chunks were observed on the fibre surface. This indicates that the capsules content reduces drastically after washing and drycleaning treatments. 
TABLE 1: Chemical composition of natural essential oils.

\begin{tabular}{|c|c|c|c|c|}
\hline & Chemical compounds & $\begin{array}{l}\text { Molecular } \\
\text { formula }\end{array}$ & $\begin{array}{l}\text { Molecular } \\
\text { weight }\end{array}$ & $\begin{array}{c}\text { Composition } \\
(\%)\end{array}$ \\
\hline \multirow{6}{*}{ Eucalyptus oil } & Oxirane, 2,2-dimethyl-3-propyl & $\mathrm{C}_{7} \mathrm{H}_{14} \mathrm{O}$ & 114 & 2.32 \\
\hline & $\alpha$-Pinene & $\mathrm{C}_{10} \mathrm{H}_{16}$ & 136 & 11.20 \\
\hline & Benzene, 1-methyl-2-(1-methylethyl) & $\mathrm{C}_{10} \mathrm{H}_{14}$ & 134 & 4.03 \\
\hline & Eucalyptol & $\mathrm{C}_{10} \mathrm{H}_{18} \mathrm{O}$ & 154 & 82.46 \\
\hline & Pentan-2-ol, 4-allyloxy-2-methyl- & $\mathrm{C}_{9} \mathrm{H}_{18} \mathrm{O}_{2}$ & 158 & 13.10 \\
\hline & 3,4-Hexanediol, 2,5-dimethyl & $\mathrm{C}_{8} \mathrm{H}_{18} \mathrm{O}_{2}$ & 146 & 6.83 \\
\hline \multirow{6}{*}{ Citronella oil } & 6-Octen-1-ol, 3,7-Dimethyl & $\mathrm{C}_{10} \mathrm{H}_{18} \mathrm{O}$ & 154 & 17.35 \\
\hline & 6-Octenal, 3,7-Dimethyl & $\mathrm{C}_{10} \mathrm{H}_{20} \mathrm{O}$ & 156 & 7.26 \\
\hline & $\begin{array}{l}\text { 2,6-Octadien-1-ol, 3,7-Dimethyl-(E) } \\
\text { (Citronellal) }\end{array}$ & $\mathrm{C}_{10} \mathrm{H}_{18} \mathrm{O}$ & 154 & 44.95 \\
\hline & 2,6-Octadienal, 3,7-dimethyl & $\mathrm{C}_{10} \mathrm{H}_{16} \mathrm{O}$ & 152 & 6.24 \\
\hline & 2,6-Octadien-1-ol, 3,7-dimethyl-acetate & $\mathrm{C}_{12} \mathrm{H}_{20} \mathrm{O}_{2}$ & 196 & 4.25 \\
\hline & 3-Ethyl-2,2-Dimethyl-Oxirane & $\mathrm{C}_{6} \mathrm{H}_{12} \mathrm{O}$ & 100 & 3.90 \\
\hline \multirow{9}{*}{ Lavender oil } & 3,4-Hexanediol, 2,5-Dimethyl & $\mathrm{C}_{8} \mathrm{H}_{18} \mathrm{O}_{2}$ & 146 & 2.11 \\
\hline & 1R- $\alpha$-Pinene & $\mathrm{C}_{10} \mathrm{H}_{16}$ & 136 & 14.04 \\
\hline & $\alpha$-Pinene & $\mathrm{C}_{10} \mathrm{H}_{16}$ & 136 & 2.20 \\
\hline & 1,6-Octadien-3-ol, 3,7-Dimethyl & $\mathrm{C}_{10} \mathrm{H}_{18} \mathrm{O}$ & 154 & 14.11 \\
\hline & $\begin{array}{l}\text { Bicyclo [2.2.1]heptan-2-one, } \\
\text { 1,7,7-trimethyl, (1S) }\end{array}$ & $\mathrm{C}_{10} \mathrm{H}_{16} \mathrm{O}$ & 152 & 3.6 \\
\hline & Isononyl ester & $\mathrm{C}_{11} \mathrm{H}_{22} \mathrm{O}_{2}$ & 186 & 25.93 \\
\hline & $(1 \mathrm{~s}, 2 \mathrm{r}, 4 \mathrm{r})$-beta-Fenchol & $\mathrm{C}_{10} \mathrm{H}_{18} \mathrm{O}$ & 154 & 8.29 \\
\hline & $\begin{array}{l}\text { 1,6-Octadien-3-ol, 3,7-Dimethyl-, } \\
\text { 2-Aminobenzoate }\end{array}$ & $\mathrm{C}_{17} \mathrm{H}_{23} \mathrm{NO}_{2}$ & 273 & 10.94 \\
\hline & $\begin{array}{l}\text { 2-Norpinene-2-ethanol, 6,6-Dimethyl-, } \\
\text { acetate }\end{array}$ & $\mathrm{C}_{13} \mathrm{H}_{20} \mathrm{O}_{2}$ & 208 & 14.88 \\
\hline
\end{tabular}

TABle 2: Particle size analysis.

\begin{tabular}{lccc}
\hline Microcapsules & $\begin{array}{c}\text { Surface } \\
\text { weighted } \\
\text { mean }(\mu \mathrm{m})\end{array}$ & $\begin{array}{c}\text { Volume } \\
\text { weighted } \\
\text { mean }(\mu \mathrm{m})\end{array}$ & $\begin{array}{c}\text { Specific surface } \\
{\text { area }{ }^{2} / \mathrm{g}}^{2}\end{array}$ \\
\hline Eucalyptus & 3.453 & 5.556 & 1.74 \\
Lavender & 2.646 & 3.560 & 2.27 \\
Citronella & 2.984 & 3.762 & 2.01 \\
\hline
\end{tabular}

TABLE 3: Loading of essential oils in microcapsules.

\begin{tabular}{lcc}
\hline Microcapsules & $\begin{array}{c}\text { Solid polymer } \\
\text { content } \\
\text { in formulation \% }\end{array}$ & $\begin{array}{c}\text { Essential oil content } \\
\text { in slurry \% }\end{array}$ \\
\hline Eucalyptus & 34.45 & 24.50 \\
Citronella & 37.39 & 41.05 \\
Lavender & 36.95 & 36.00 \\
\hline
\end{tabular}

The microcapsule treated unwashed fabric sample (Table 5) shows good fragrance durability and slow release of fragrance. The fabric shown in Figure 1 released about $17-25 \%$ of the essential oil content over a prolonged period of fifteen days. The fragrance release ratings were also found to be on very strong over a prolonged period of time. All the evaluators have rated these samples to be very strong.

The Anthrenus flavipies proofing properties of treated and untreated fabric samples is shown in (Table 6). The weight loss for untreated samples was $49.73 \mathrm{mg}(32 \%)$ and several large holes can be seen on the wool fabric. The surface characteristics of the treated and untreated samples are shown in (Figure 2). Untreated fabric sample was heavily cropped and several large holes were formed, showing an inadequate resistance towards the test larvae, whereas the weight loss for unwashed eucalyptus, lavender, and citronella microcapsule treated samples were $20 \%, 12 \%$, and $10 \%$, respectively. The surface damage was also found to be less compared to the untreated sample. The activity against the test larvae was found to reduce drastically after washing and dry-cleaning of the samples. This can be attributed to the removal of microcapsules from the fabric surface as evidenced from the SEM images (Figure 1) and subsequent reduction in the essential oils present on the fabric samples as shown in (Table 4). The commercial Anthrenus flavipies proofing chemical permethrin gives satisfactory protection to wool fabric. The weight loss for permethrin finish unwashed, washed, and dry-cleaned fabric samples was found to be $2 \%$, $4 \%$, and $7 \%$, respectively. 


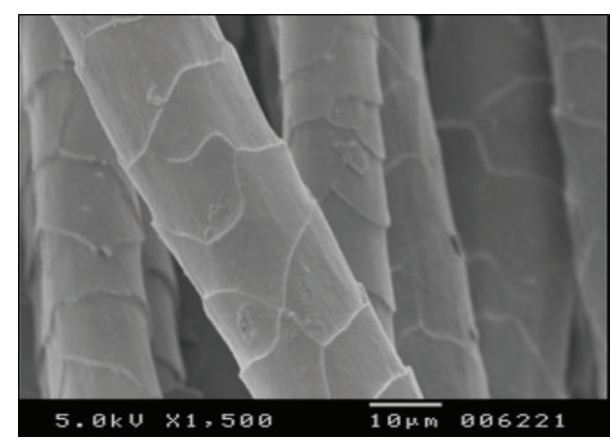

(a)

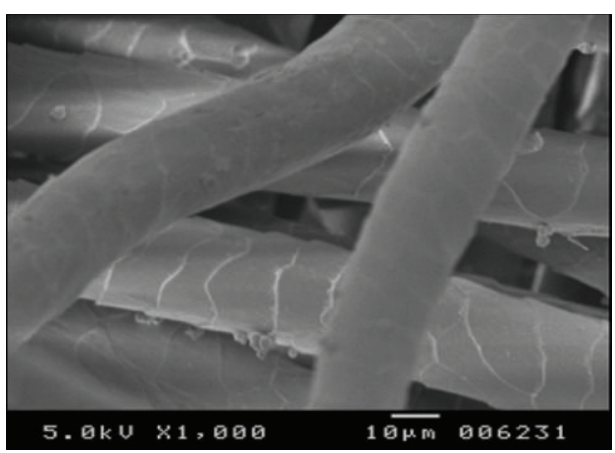

(c)

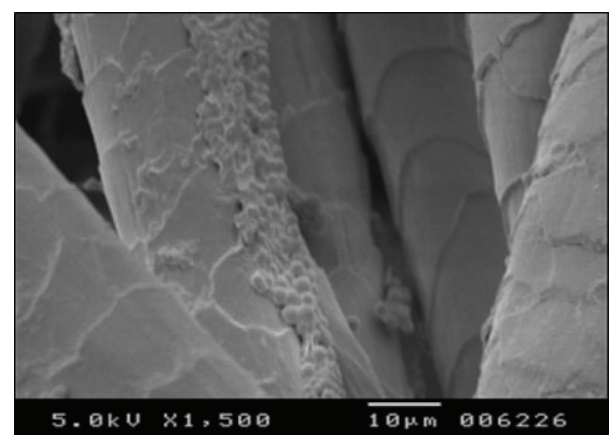

(b)

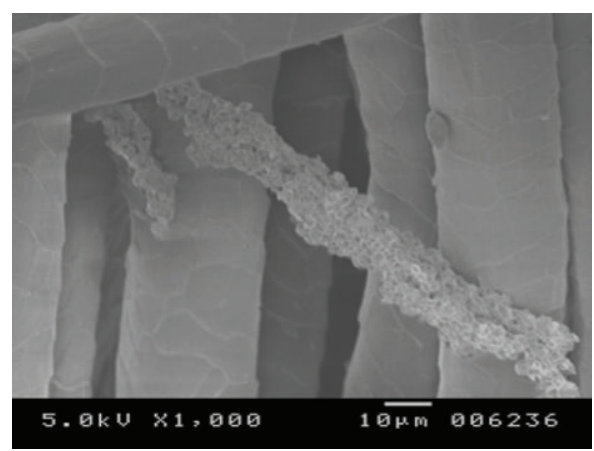

(d)

Figure 1: SEM images of (a) untreated, (b) citronella unwashed, (c) washed, and (d) dry-cleaned fabric samples.

TABLE 4: Chemical content, fragrance ratings, and durability of finish to washing and dry-cleaning.

\begin{tabular}{lccc}
\hline Samples & Chemical content (\%) & Fragrance ratings & Chemical release (\%) \\
\hline Eucalyptus unwashed & 0.1944 & Very strong & - \\
Washed & Traces & Very faint & 100 \\
Dry-cleaned & 0.0211 & Moderate & 89 \\
Citronella unwashed & 0.3659 & Very strong & - \\
Washed & Traces & Very faint & 100 \\
Dry-cleaned & 0.0489 & Moderate & 87 \\
Lavender unwashed & 0.4683 & Very strong & - \\
Washed & Traces & Very faint & 100 \\
Dry-cleaned & 0.0329 & Moderate & 93 \\
Permethrin Unwashed & 0.0187 & - & - \\
Washed & 0.0104 & - & 44 \\
Dry-cleaned & 0.0080 & - & 57 \\
\hline
\end{tabular}

Anthrenus flavipies repellent properties of the finished fabric are shown in (Table 7). In this study, larvae were provided with a choice of eating an untreated fabric kept alongside the treated one. Anthrenus flavipies were observed to migrate towards untreated samples and they preferred eating untreated sample compared to its treated counterpart irrespective of treatment type given to the samples. This indicates that eucalyptus, lavender, or citronella possess repellent activity against the larvae of Anthrenus flavipies. Lavender and citronella show more repellence compared to eucalyptus finished unwashed fabric sample. Two untreated samples placed side by side showed weight loss of 30-40\% whereas weight loss of eucalyptus, lavender, and citronella treated unwashed samples were $30 \%, 9 \%$, and 5\%, respectively, with weight loss of accompanied untreated sample was in the range of $50-65 \%$. The washing and dry-cleaning process were found to reduce the repellency activity. The weight loss for permethrin treated unwashed, washed, and drycleaned samples were found to be negligible compared to their untreated counterparts.

Sample photographs (Figure 3) depict the extent of surface damage after 14 days of testing. Representative untreated sample shows heavy surface cropping compared to the treated counterpart indicating their preference to the untreated one. 


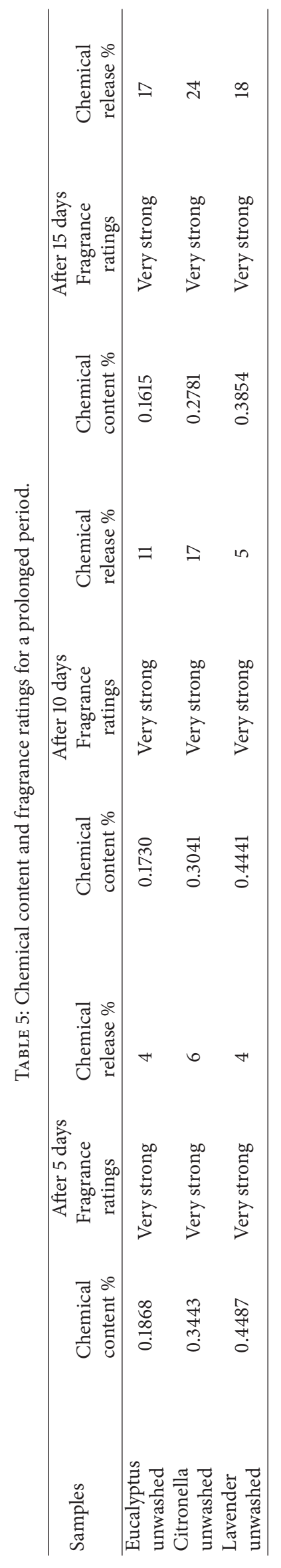




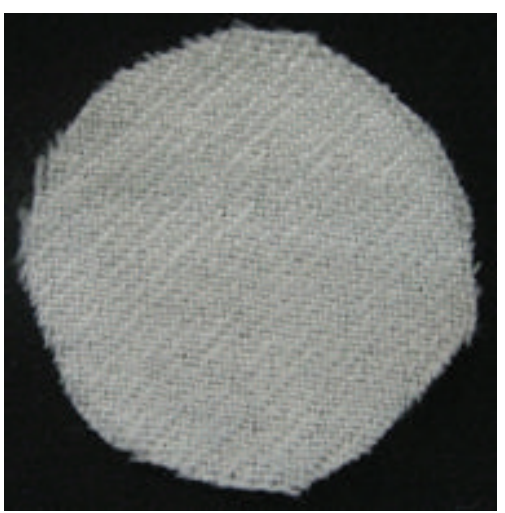

(a)

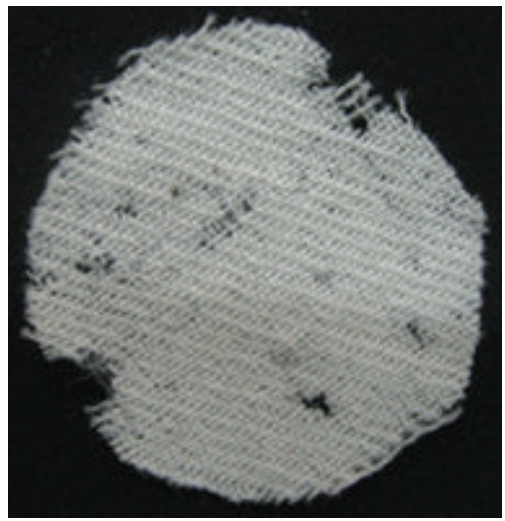

(d)

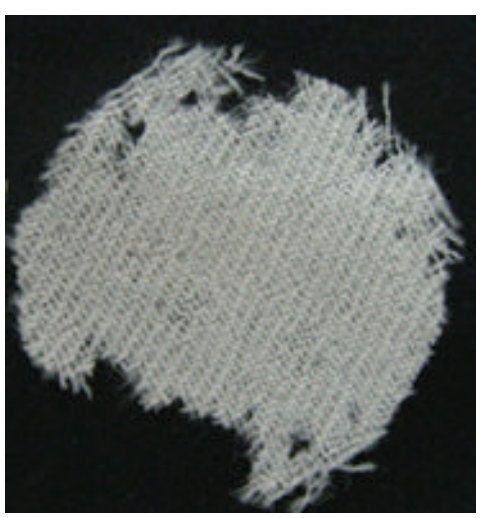

(b)

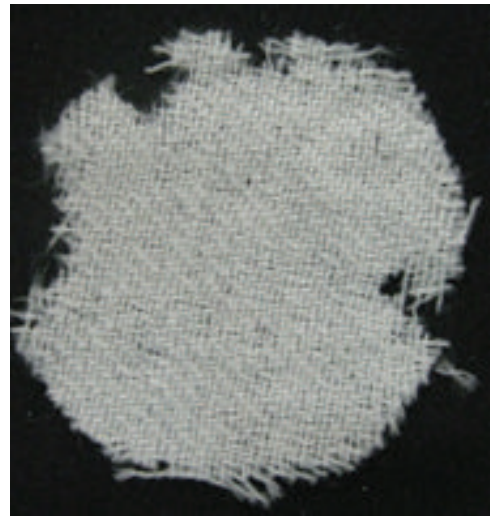

(e)

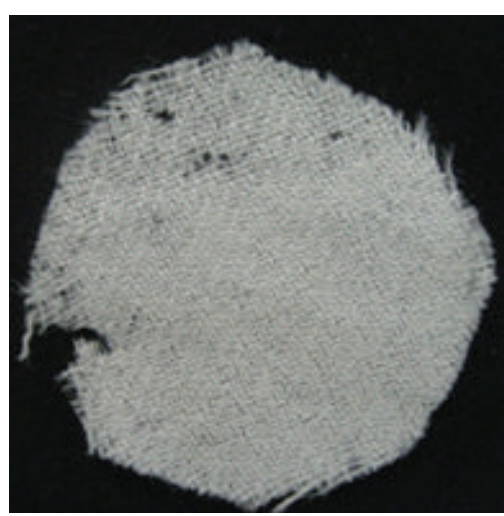

(c)

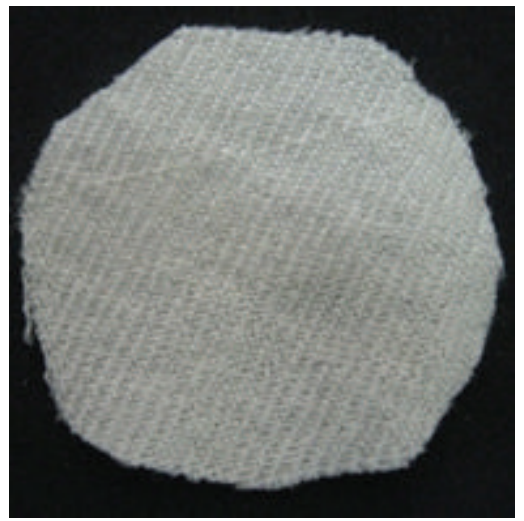

(f)

Figure 2: Samples after 14 days of exposure to the larvae of Anthrenus flavipies (proof testing): (a) control, (b) untreated, (c) citronella, (d) lavender, (e) eucalyptus, and (f) permethrin treated unwashed fabric samples.

TABLE 6: Anthrenus flavipies proof properties of fabrics.

\begin{tabular}{lccccc}
\hline $\begin{array}{l}\text { Sample placed } \\
\text { in Petri dish }\end{array}$ & $\begin{array}{c}\text { Weight loss } \\
(\mathrm{mg})\end{array}$ & Surface cropping & $\begin{array}{c}\text { Visual observations } \\
\text { Surface holes }\end{array}$ & Larval condition & Rating/Remark \\
\hline Untreated & 49.73 & 4. very heavy cropping & D. several large holes & All alive & 4D/inadequately resistant \\
Eucalyptus unwashed & 35.27 & 4. very heavy cropping & D. several large holes & All alive & 4D/inadequately resistant \\
Washed & 42.02 & 4. very heavy cropping & D. several large holes & All alive & 4D/inadequately resistant \\
Dry-cleaned & 38.33 & 4. very heavy cropping & D. several large holes & All alive & 4D/inadequately resistant \\
Lavender unwashed & 26.11 & 4. very heavy cropping & D. several large holes & Two dead & $4 \mathrm{D} /$ inadequately resistant \\
Washed & 43.56 & 4. very heavy cropping & D. several large holes & All alive & 4D/inadequately resistant \\
Dry-cleaned & 32.36 & 4. very heavy cropping & D. several large holes & All alive & 4D/inadequately resistant \\
Citronella unwashed & 23.60 & 4. very heavy cropping & D. several large holes & All alive & 4D/inadequately resistant \\
Washed & 36.41 & 4. very heavy cropping & D. several large holes & All alive & 4D/inadequately resistant \\
Dry-cleaned & 25.52 & 4. very heavy cropping & D. several large holes & All alive & 4D/inadequately resistant \\
Permethrin unwashed & 3.75 & 1. no detectable damage & A. no detectable damage & Two dead & $1 \mathrm{~A} /$ satisfactorily resistant \\
Washed & 11.33 & 4. very heavy cropping & D. several large holes & Two dead & $1 \mathrm{~A} /$ satisfactorily resistant \\
Dry-cleaned & 13.45 & 1. no detectable damage & A. no detectable damage & One dead & $1 \mathrm{~A} /$ satisfactorily resistant \\
\hline
\end{tabular}

\section{Conclusion}

The chemical composition study using GC-MS shows eucalyptol (82\%), citronellal (45\%), and isononyl ester (26\%) as the major constituents of eucalyptus, citronella, and lavender essential oils. The loading of essential oils in microcapsules were found to be in the range of $24-41 \%$ with mean particle size of $3-5 \mu \mathrm{m}$. The SEM images confirm uniform distribution of microcapsules over the fabric surface. The microcapsule treated unwashed fabric samples have shown 


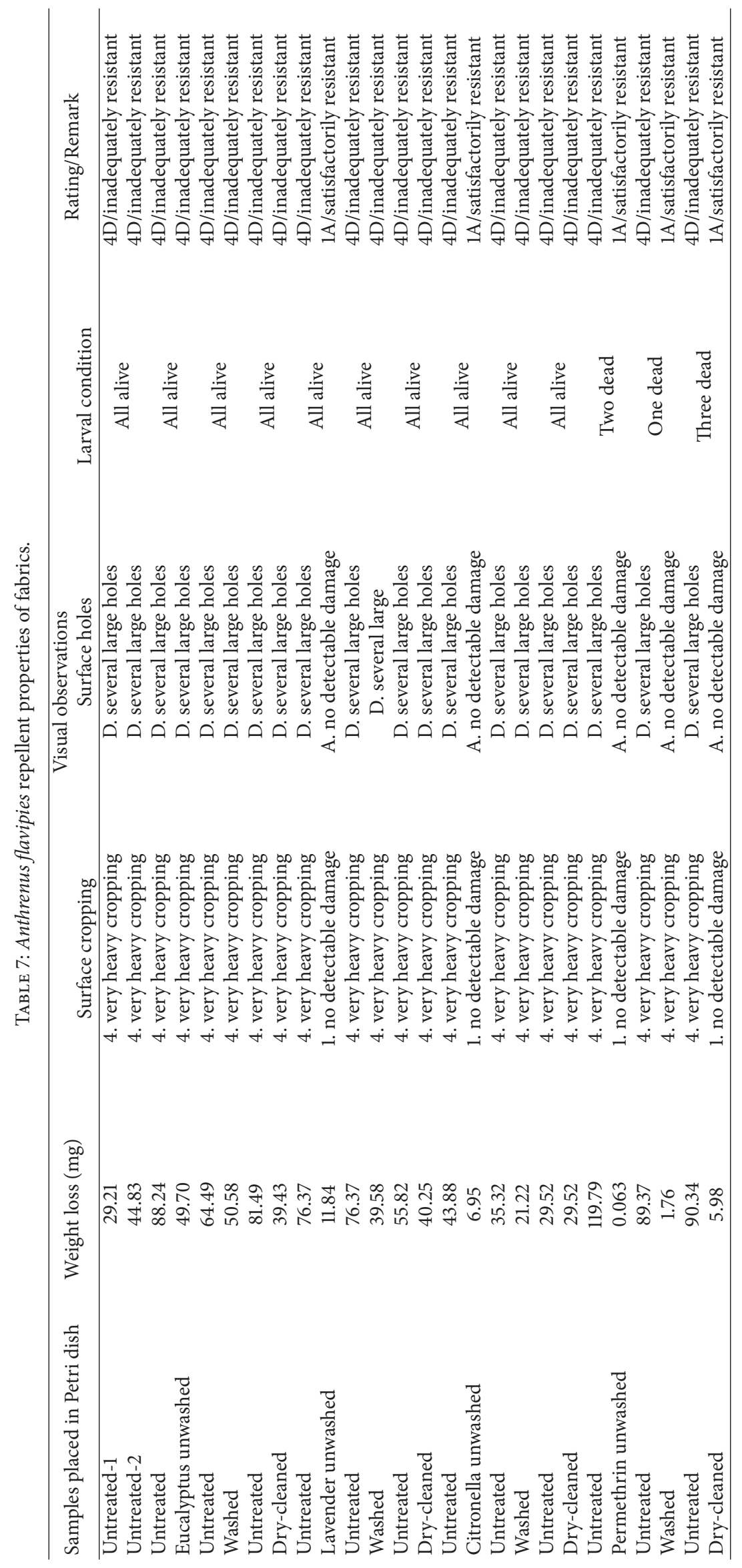




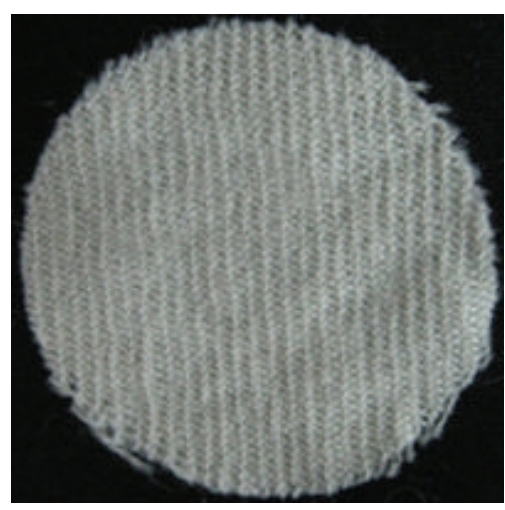

(a)

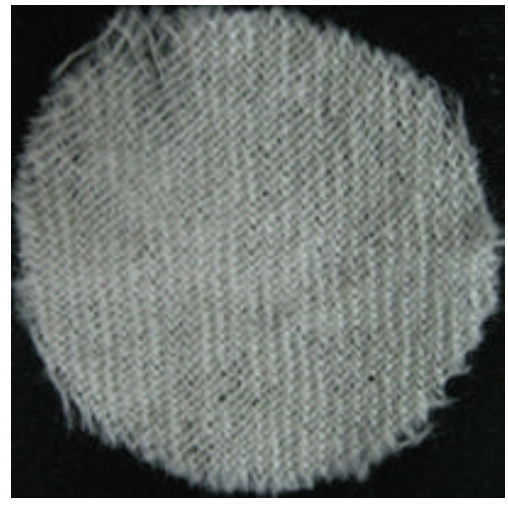

(d)

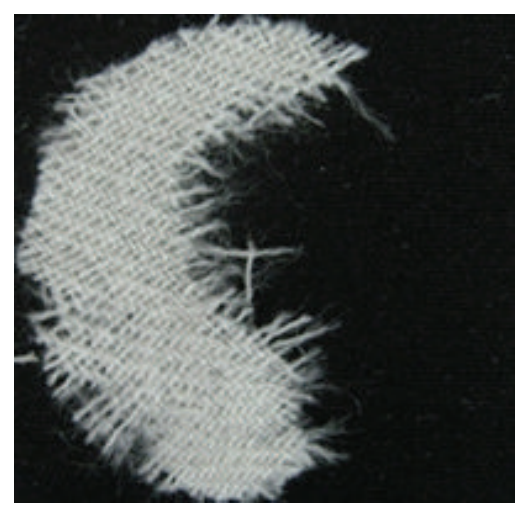

(b)

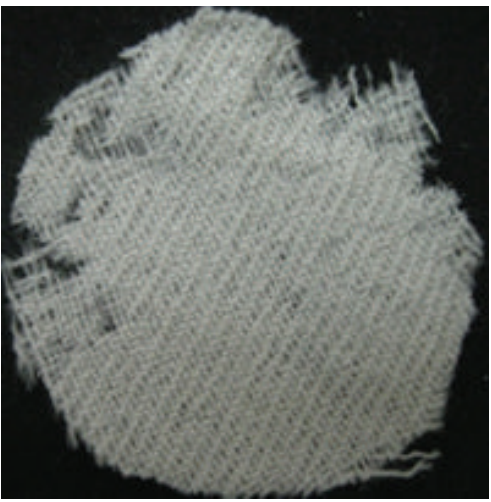

(e)

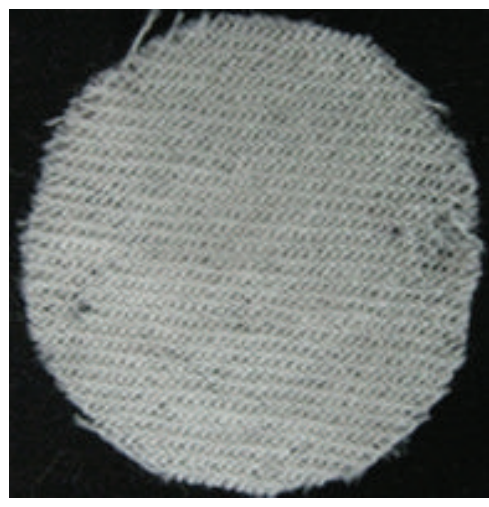

(c)

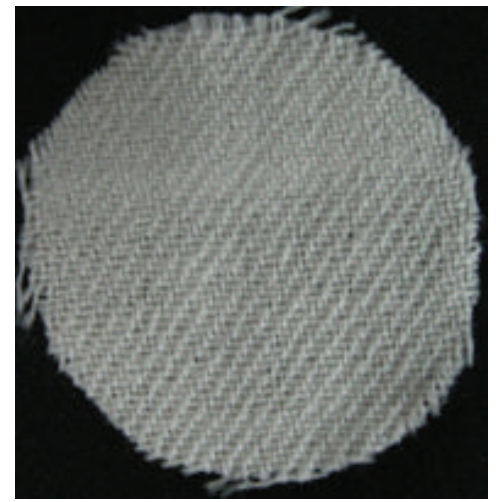

(f)

FIGURE 3: Samples after 14 days of exposure to the larvae of Anthrenus flavipies (repellency testing): (a) control, (b) untreated, (c) citronella, (d) lavender, (e) eucalyptus, and (f) permethrin treated unwashed fabric samples.

good fragrance durability and slow release of fragrance. Wool fabrics finished with microcapsules of citronella, lavender, and eucalyptus essential oils provides good resistance against the Larvae of carpet beetle Anthrenus flavipies (LeConte); however, the activity of the microencapsulated essential oils is less compared to commercial insect resist agent permethrin. The effectiveness of microcapsule finish reduces after washing and dry-cleaning treatments. The microcapsule treated samples performs better when tested along with the untreated samples. It was observed that Anthrenus flavipies (LeConte) prefer eating untreated samples than their treated counterpart. The performance of essential oils as a natural alternative repellent against the test larvae was in the order citronella > lavender > eucalyptus. As permethrin is highly toxic to the aquatic life, natural essential oils provide a natural, biodegradable, and less toxic alternative with an added advantage of pleasant fragrance over a long period of time.

\section{Conflict of Interests}

The authors declare that there is no conflict of interests regarding the publication of this paper.

\section{References}

[1] C. O. Clark, "The protection of animal fibres against clothes moths and dermestid beetles," Journal of Textile Institute, vol. 19, pp. 295-320, 1928.

[2] R. S. Hartley, F. F. Elsworth, and J. Barrit, "The mothproofing of wool," Journal of the Society of Dyers and Colourists, vol. 59, no. 12, pp. 266-271, 1943.

[3] M. Lipson and J. R. McPhee, "The mothproofing of wool with dieldrin," Textile Research Journal, vol. 28, no. 8, pp. 679-686, 1958.

[4] R. J. Mayfield, "Mothproofing," Textile Progress, vol. 11, no. 4, pp. $1-11,1982$.

[5] D. E. Wells and S. J. Johnstone, "High performance liquid chromatography of polychloro-2-(chloromethyl sulphonamido) diphenyl ethers and their impurities in the mothproofing agent, Eulan WA New, and in water," Journal of Chromatographic Science, vol. 19, no. 3, pp. 137-143, 1981.

[6] P. A. Duffield, "Mothproofing with permethrin," Pesticide Science, vol. 8, no. 3, pp. 279-283, 1977.

[7] S. W. Carter and P. A. Duffield, "Preliminary evaluation of the pyrethroid NRDC 143 as an industrial mothproofer," The Journal of The Textile Institute, vol. 67, no. 3, pp. 77-81, 1976. 
[8] D. Wang, H. Naito, and T. Nakajima, "The toxicity of fenitrothion and permethrin," in Insecticides-Pest Engineering, F. Perveen, Ed., pp. 85-98, InTech, Shanghai, China, 2012.

[9] R. D. O’Brien, "Insecticides and environmental health," in Insecticides, Action and Metabolism, R. D. O’Brien, Ed., pp. 291304, Academic Press, New York, NY, USA, 1967.

[10] I. Yamamoto, "Problems in mode of action of pyrethroids," in Biochemical Toxicology of Insecticides, R. D. O'Brien and I. Yamamoto, Eds., pp. 193-200, Academic Press, New York, NY, USA, 1970.

[11] W. F. Barthel, "Toxicity of pyrethrum and its constituents to mammals," in Pyrethrum, The Natural Insecticides, J. E. Casida, Ed., pp. 123-142, Academic Press, New York, NY, USA, 1973.

[12] M. F. Maia and S. J. Moore, "Plant-based insect repellents: a review of their efficacy, development and testing," Malaria Journal, vol. 10, no. 1, article S11, 2011.

[13] E. K. Patel, A. Gupta, and R. J. Oswal, "A review on: mosquito repellent methods," International Journal of Pharmaceutical, Chemical and Biological Sciences, vol. 2, no. 3, pp. 310-317, 2012.

[14] N. Rani, A. Wany, A. S. Vidyarthi, and D. M. Pandey, "Study of Citronella leaf based herbal mosquito repellents using natural binders," Current Research in Microbiology and Biotechnology, vol. 1, no. 3, pp. 98-103, 2013.

[15] D. R. Barnard and R. Xue, "Laboratory evaluation of mosquito repellents against Aedes albopictus, Culex nigripalpus, and Ochlerotatus triseriatus (Diptera: Culicidae)," Journal of Medical Entomology, vol. 41, no. 4, pp. 726-730, 2004.

[16] M. Arancibia, A. Rabossi, P. A. Bochicchio et al., "Biodegradable films containing clove or citronella essential oils against the mediterranean fruit fly Ceratitis capitata (Diptera: Tephritidae)," Journal of Agriculture and Food Technology, vol. 3, no. 3, pp. 1-7, 2013.

[17] International Wool Secretariat, "ETB-32 Initial concentration levels (ICLs) for insects resist agents on wool carpets, carpet yarns, rug yarns and upholstery," Technical Information Bulletin, no. $1,1994$. 

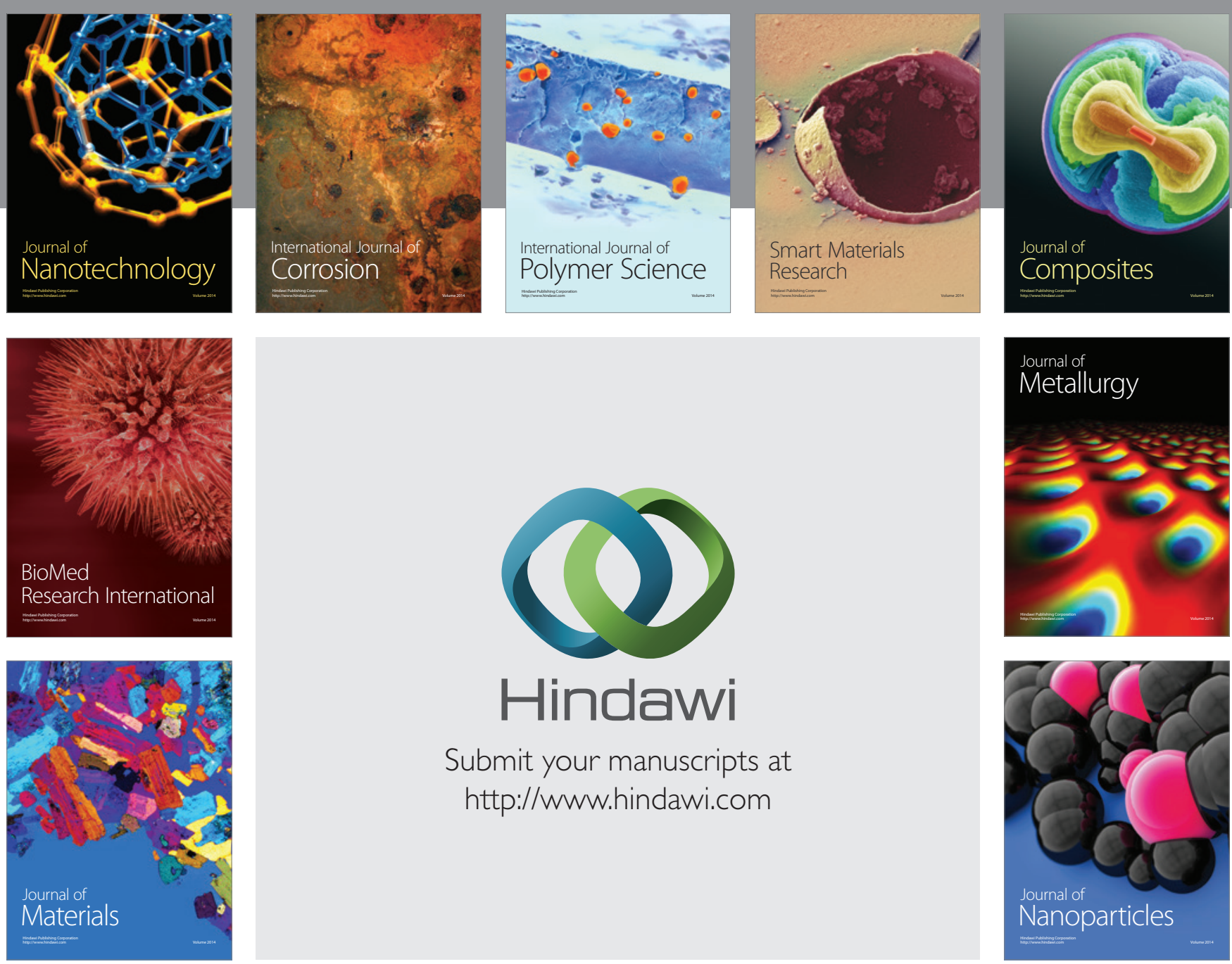

Submit your manuscripts at http://www.hindawi.com
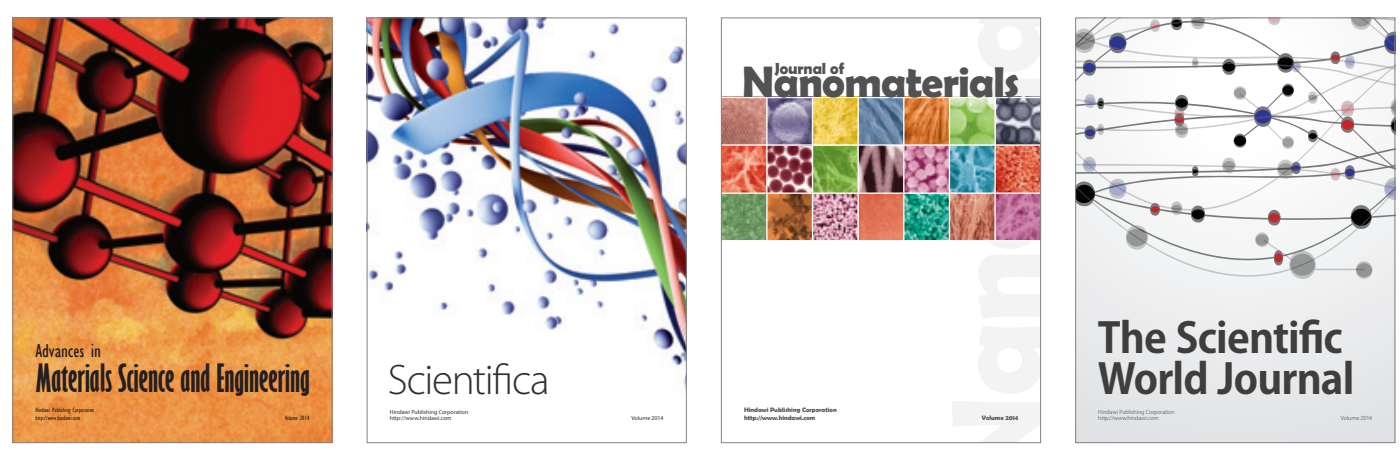

\section{The Scientific World Journal}
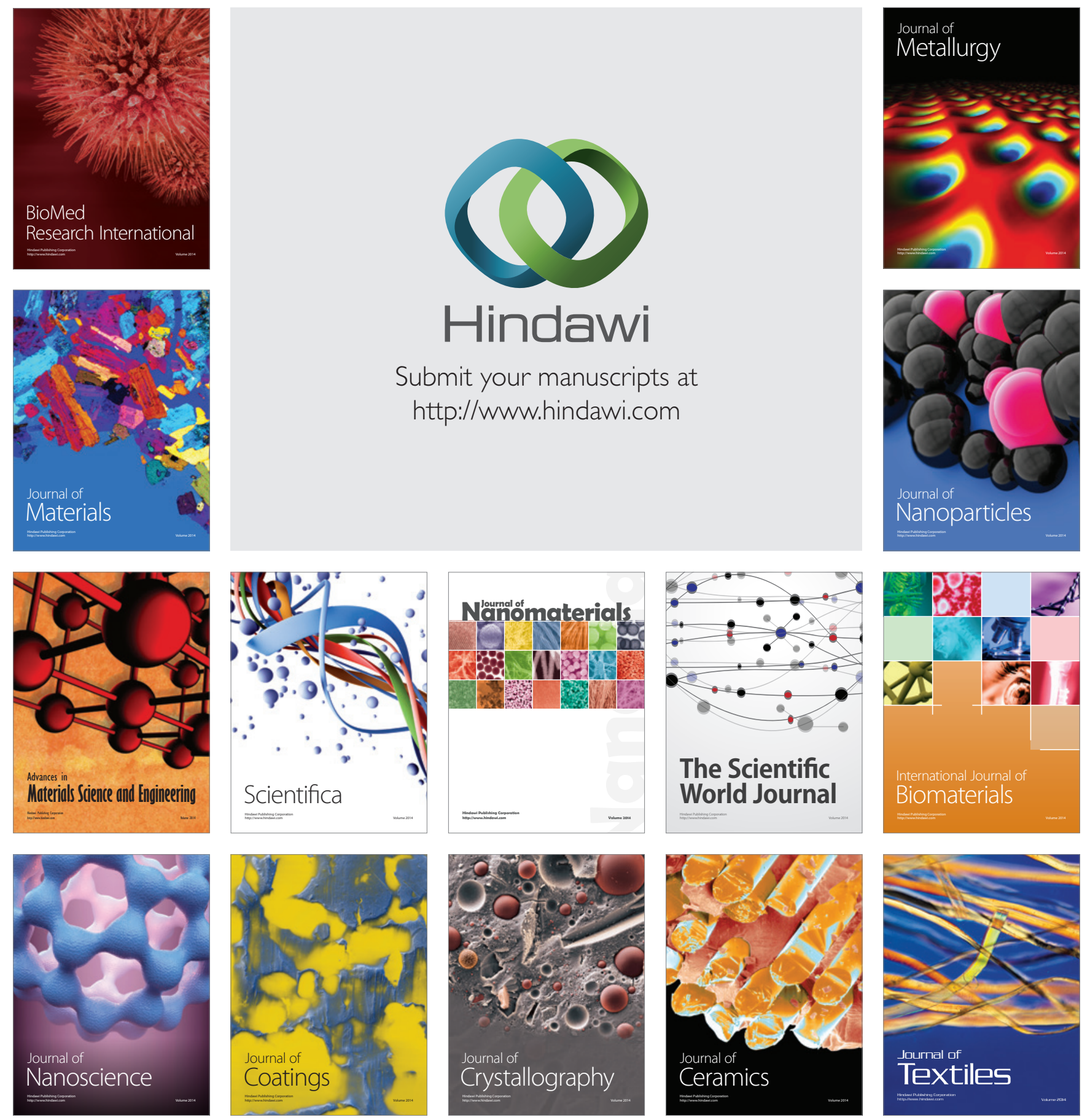